\title{
Can the Weak Surface Currents of the Cape Verde Frontal Zone Be Measured With Altimetry?
}

\author{
VICTOR ZLOTNICKI \\ Jet Propulsion Laboratory, California Institute of Technology, Pasadena \\ Gerold Siedler AND Birgit KLEIN
}

Institut für Meereskunde, Universität Kiel, Kiel, Germany

\begin{abstract}
Three data types are compared in the low-current-velocity regime in the southeastern North Atlantic, between $12^{\circ} \mathrm{N}$ and $30^{\circ} \mathrm{N}, 29^{\circ} \mathrm{W}$ and $18^{\circ} \mathrm{W}$ : Geosat altimetric sea level and derived surface geostrophic velocities, shallow current meter velocities, and dynamic heights derived from hydrographic data from cruises 4, 6, and 9 of the research vessel Meteor. The four current meter daily time series, at depths around $200 \mathrm{~m}$, were smoothed over 1 month; the altimetric geostrophic velocities were computed from sea surface slopes over $142 \mathrm{~km}$ every 17 days. The correlation coefficients between the current meter and altimetric geostrophic velocities range between 0.64 and 0.90 for the moorings near $29^{\circ} \mathrm{N}$ but between 0.32 and 0.71 for the two around $21^{\circ} \mathrm{N}$; the associated rms discrepancies between the two measurement types range between 1.5 and $4.4 \mathrm{~cm} / \mathrm{s}$, which is $49 \%$ to $127 \%$ of the rms of the respective current meter time series. Dynamic heights relative to $1950 \mathrm{dbar}$ for the months of November $1986\left(d_{\mathrm{M} 4}\right)$, November $1987\left(d_{\mathrm{M} 6}\right)$, and February $1989\left(d_{\mathrm{M} 9}\right)$ were computed from Meteor cruises 4,6 , and 9 . Both dynamic heights and altimetric heights $\left(h_{\mathrm{M} 4}, h_{\mathrm{M} 6}, h_{\mathrm{M} 9}\right)$ were averaged over $1^{\circ}$ boxes for the duration of each cruise. Differences $d_{\mathrm{M} 4}-d_{\mathrm{M} 6}$ and $d_{\mathrm{M} 9}-d_{\mathrm{M} 6}$ were computed only at bins where at least one station from both cruises existed. Assuming that dynamic heights $d$ in dynamic centimeters are equivalent to sea level $h$ in centimeters, the standard deviation $\sigma$ of the differences $\left(\left(h_{\mathrm{M} 4}-h_{\mathrm{M} 6}\right)-\left(d_{\mathrm{M} 4}-d_{\mathrm{M} 6}\right)\right)$ and corresponding M9 - M6 values was $2.1 \mathrm{~cm}$. This value (squared) is only $13 \%$ of the $(5.8 \mathrm{~cm})^{2}$ variance of the dynamic height differences and is indistinguishable from the 2.7 - to 5.6 -cm natural variability of sea level in the area expected between the times when the ship and the satellite sampled the ocean. The areally averaged discrepancy for M9 - M6 was only $0.7 \mathrm{~cm}$, but the corresponding value for M4 - M6 was $5.2 \mathrm{~cm}$. A systematic difference between the water vapor corrections used before and after July 1987 is responsible for the M4 - M6 difference. The average M4 - M6 discrepancy is only $0.1 \mathrm{~cm}$ using the Fleet Numerical Oceanography Center correction, with a standard deviation of $3.1 \mathrm{~cm}$. In spite of the underlying differences in sampling and physics, including unknown barotropic components not included in our hydrographic dynamic heights, and in data errors, including water vapor, ionospheric, and orbital effects on the altimetry, consistent interannual changes of the mean sea level from the independently obtained altimetric and hydrographic data sets are obtained, and correlated seasonal changes in surface currents are observed with both altimetry and current meters.
\end{abstract}

\section{INTRODUCTION}

Most studies with Geosat satellite altimeter data over the last several years have concentrated on the large signals associated with western boundary currents [e.g., Kelly and Gille, 1990] or equatorial currents [e.g., Arnault et al., 1990]. Here we compare Geosat data with hydrographic and current meter data in a region with much smaller signals. The primary aim is to test whether altimetric data are sufficiently precise for determining the flow variability on scales from months to several years in a low-energy regime.

Altimeters, moored current meters, and conductivitytemperature-depth probes (CTDs) measure different properties of the oceanic flow. The surface slopes observed by altimeters yield geostrophic surface velocities, while current meters provide the total velocity (geostrophic and Ekman constituents, internal waves, etc.) at a certain depth. The geopotential anomaly (dynamic height) distribution obtained from hydrographic data sets supplies information on geostrophic velocities relative to a deep reference level, unless

Copyright 1993 by the American Geophysical Union.

Paper number 92JC02729.

0148-0227/93/92JC-02729\$05.00 the configuration of stations allows a beta spiral or inverse calculation [Stommel and Schott, 1977; Wunsch, 1978; Davis, 1978]. In addition to these differences, a comparison has to take into account the differences in temporal and spatial sampling inherent in the three types of observations, as well as their relation to the variability described above. The goals we had in comparing the three types of data include answers to these questions: (1) Can seasonal and interannual variations of geostrophic ocean currents in such a low-energy regime be determined from Geosat altimetry? (2) Can Geosat altimetry provide surface currents on a monthly scale that are consistent with what current meter moorings observe, and if so, can we combine the two and hydrography to generate believable monthly maps?

\section{The RegION}

The observational area (Figure 1) covers the southwestern part of the North Atlantic anticyclonic subtropical gyre [Stramma, 1984a, b] and the transition to the shadow zone [Luyten et al., 1983] where a cyclonic gyre can be expected [Siedler et al., 1992]. The near-surface currents are composed of the weak mean subtropical gyre flow indicated in the inset map of Figure 1 and variable contributions on different scales. 


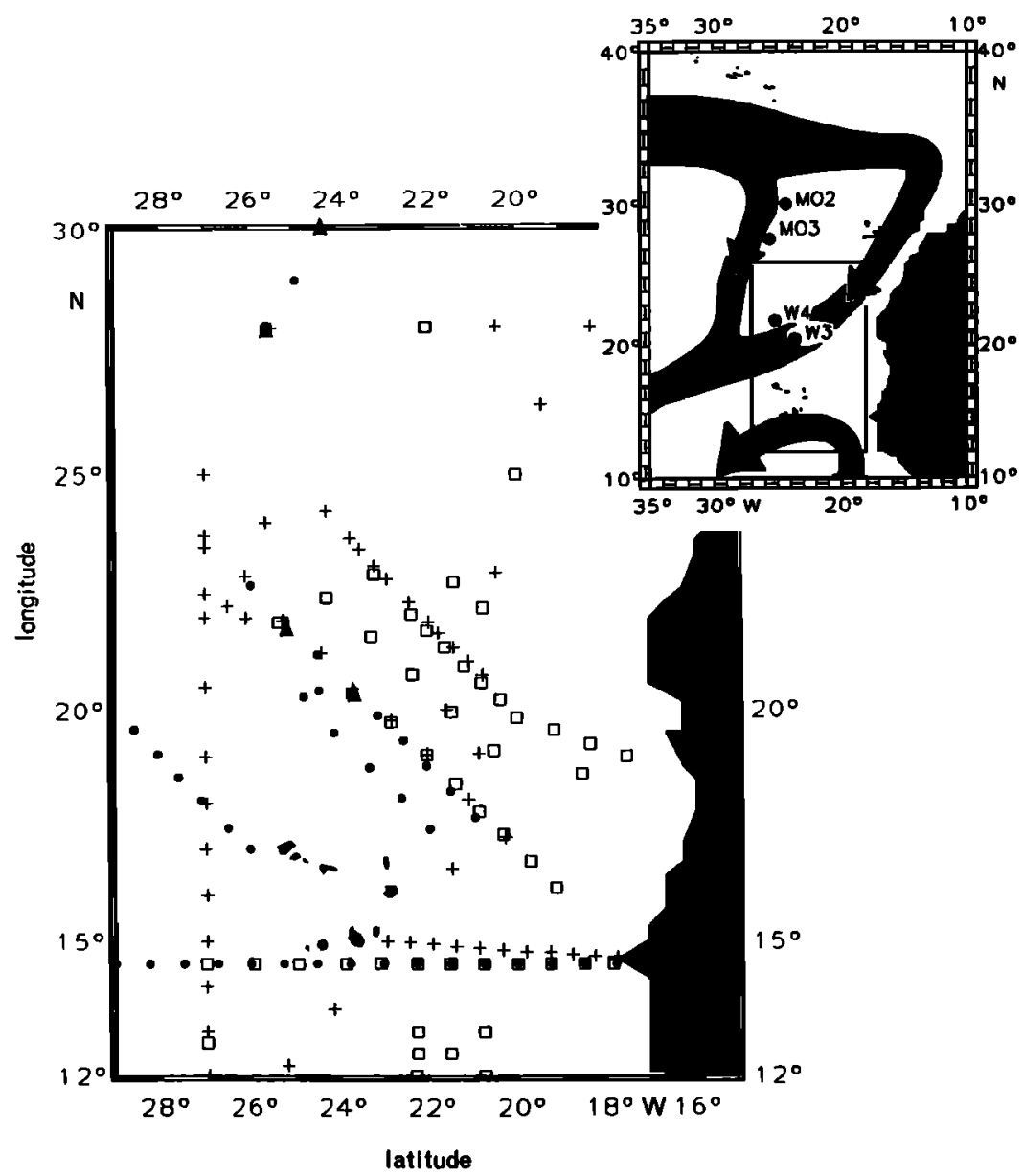

Fig. 1. Distribution of hydrographic stations during three Meteor cruises (pluses, M4; squares, M6; circles, M9), and current meter moorings (triangles). The inset map indicates the schematic upper ocean circulation.

The main current core is part of the Canary Current-North Equatorial Current system in the Cape Verde Frontal Zone [Zenk et al., 1991; Fiekas et al., 1992]. The temperature and salinity gradients at the front separating North and South Atlantic Central waters almost compensate each other with respect to density [Barton, 1987]. The core of the geostrophic current in the frontal zone is found approximately $200 \mathrm{~km}$ south of the thermohaline front [Stramma and Müller, 1989]. Earlier studies of the current variability in this region indicated the existence of mesoscale perturbations related to baroclinic instability of the current core, with dominating scales of 100 to 250 days and 100 to $200 \mathrm{~km}$ [Onken and Klein, 1991]. Seasonal and longer-term variability can also be expected. Typical mean near-surface speeds in this region are $1 \mathrm{~cm} \mathrm{~s}^{-1}$, typical mesoscale variability reaches $20 \mathrm{~cm} \mathrm{~s}^{-1}$ [Müller and Siedler, 1992], and typical semidiurnal tidal signals are $1-3 \mathrm{~cm} \mathrm{~s}^{-1}$ [Siedler and Paul, 1991].

\section{Altimetric Data}

An abundant literature exists on the use of Geosat altimetry, including two special issues of the Journal of Geophysical Research (volume 95, numbers C3 and C10, 1990); hence only a brief overview, highlighting the differences between the processing performed here and other types, is given below. The geophysical data record CD-ROMs
[Cheney et al., 1991] were used. They differ from the older version [Cheney et al., 1987] in the presence of the more accurate Goddard Earth Model (GEM) T2 orbit [Haines et al., 1990], water vapor corrections derived from TIROS operational vertical sounder (TOVS) data [Emery et al., 1990] prior to July 1987 and from special sensor microwave imager (SSM/I) data [Wentz, 1988, 1989] after that date, and the correction of software errors in the computation of Schwiderski's tidal model (R. E. Cheney, personal communication, 1991). These data were edited for spikes and regridded to a uniform set of along-track latitudes [Zlotnicki et al., 1989, 1990].

The GEM-T2 orbit, like its predecessors, is the result of a dynamically consistent computation, where the satellite's orbital parameters are adjusted to the tracking data but are constrained to obey the equations of motion of the satellite subject to models of the forces (gravity, drag, solar pressure, etc.) acting on the satellite. Most improvements are associated with improved models of the forces, especially the gravity field [e.g., Marsh et al., 1990; Tapley, 1989]. All such dynamically consistent orbits leave residual orbit errors but absorb no ocean signal in their adjustment. Figure 2 shows the amplitude of the residual orbit error for this orbit between November 1986 and December 1987, computed as discussed below. The $1987-1988$ difference $(17.0 \mathrm{~cm}$ global rms in 1987 but $40.1 \mathrm{~cm}$ rms in 1988) is due to increased solar activity in the second half of 1988 , which increases insuffi- 


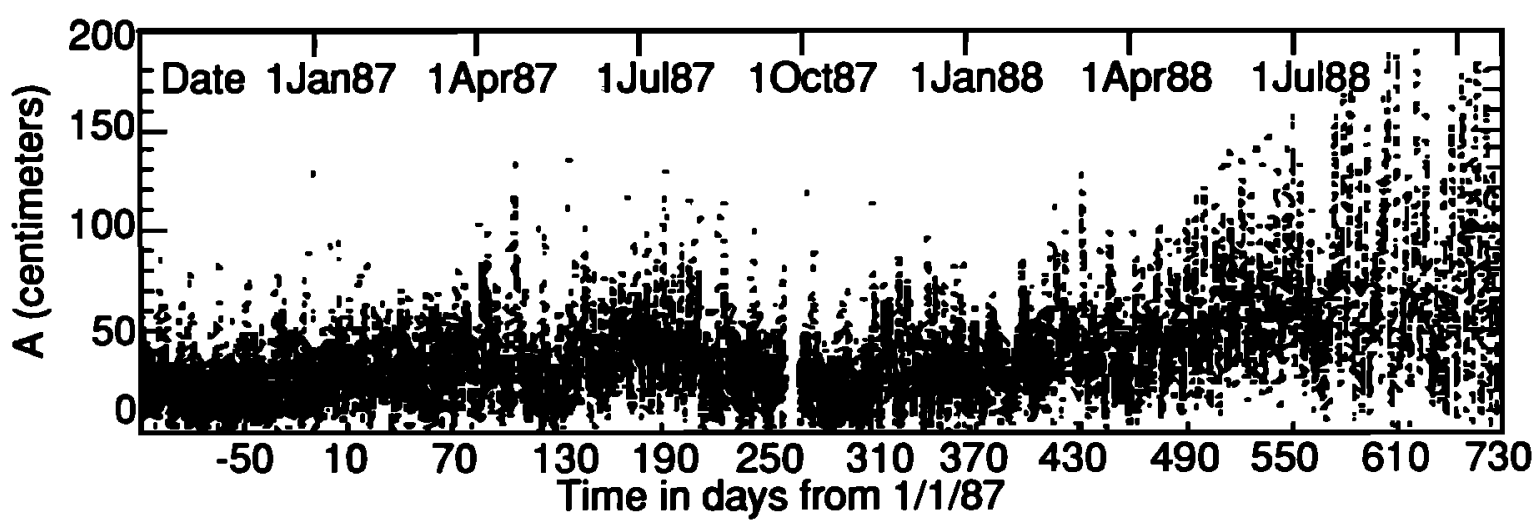

Fig. 2. Orbit error: the amplitude (in centimeters) of the once per revolution harmonic fitted to altimeter height residuals over one complete revolution, as a function of time (in days since January 1,1987 ).

ciently modeled drag forces on the satellite. While these values are much better than the $220 \mathrm{~cm}$ worldwide rms of the older Naval Astronautics Group (NAG) orbit, they must still be reduced to a few centimeters $\mathrm{cm}$ before data errors become smaller than oceanographic signals. This reduction is obtained with a variety of ad-hoc models based on the knowledge that orbit error is strongly correlated along track with maximum energy at once per revolution [e.g., Rapp, 1983; Sandwell et al., 1986; Tai, 1991; Wunsch, 1991; D. B. Chelton and M. G. Schlax, personal communication, 1992).

For this work we computed sea level differences from the most complete repeat (see Zlotnicki [1991] for a summary of the method and handling of data gaps) and estimated orbit error with a once per revolution sinewave fitted over a complete period of the satellite (approximately $6037.5 \mathrm{~s}$ or $40,030 \mathrm{~km}$ along track); notice that this is a global adjustment, not one local to the study area. Figure 2 shows the amplitudes of those harmonics as a function of time. After orbit error removal, the mean sea level at each latitudelongitude point over 1987-1988 was computed and removed from the time series for that point. Spikes were presumed whenever sea level residuals exceeded 5 times the rms of the data either along track (fixed time within $100 \mathrm{~min}$ ) or at fixed latitude and longitude; such spikes were removed, the residual orbit correction was recomputed, and the process was iterated up to four times, or fewer if no more spikes were detected.

The final product of these steps are sea level residuals from a 2-year mean, approximately every $7 \mathrm{~km}$ along track, repeated once every 17.05 days along each track, with parallel neighboring tracks occurring some $164 \mathrm{~km}$ (at the equator) and 3.0 days later to the east, plus another set of parallel tracks in the other (ascending or descending) direction. Figure 3 shows contours of sea level rms and the altimetric data tracks through the region. Notice that this quiet region is dominated by sea level residuals of 6 to $7 \mathrm{~cm}$.

\section{Altimetry and Current Meters}

We want to relate direct subsurface current records, low-pass filtered to eliminate surface tides and internal gravity waves, with sea surface inclination changes representing the surface geostrophic flow. It was shown in earlier studies [Müller and Siedler, 1992] that the low-frequency variability in this region can be well approximated by the barotropic and the first baroclinic vertical modes, with some further improvement in the approximation when adding the second baroclinic mode. With sufficient vertical coverage of instruments at each mooring, the geostrophic surface current can be obtained by determining modal amplitudes and phases and calculating the sum of the modes at the surface.

With the existing density stratification the first- and second-order modal amplitudes do not change considerably in the upper $200 \mathrm{~m}$. A 12-month comparison based on the W4 mooring time series (Figure 1) extrapolated to the surface by fitting the barotropic and one baroclinic mode to the time series at $220,420,625,1270$, and $5070 \mathrm{~m}$ resulted in no significant differences from the uppermost meter. The Ekman depth is controlled by a shallow pycnocline between 20 and $50 \mathrm{~m}$. With the selected current meter records from 140to $220-\mathrm{m}$ depth, we thus obtain a good approximation of the surface geostrophic current while avoiding contributions of the Ekman drift current.

The depth levels, positions, and periods of observations are summarized in Table 1 , and the positions are also given

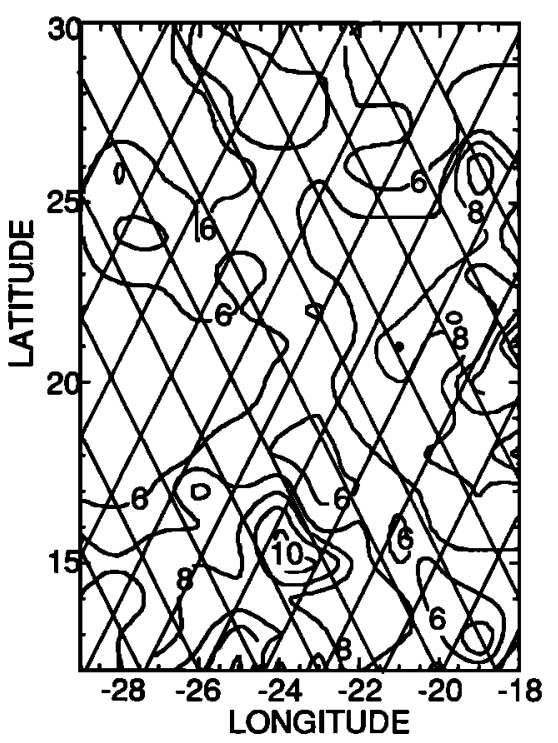

Fig. 3. Latitude-longitude plot, showing the rms variability, in centimeters, of sea level along the retained Geosat tracks, between November 1986 and March 1989. 
TABLE 1. Summary of Parameters

\begin{tabular}{|c|c|c|c|c|c|}
\hline \multirow[b]{2}{*}{ Parameter } & \multirow[b]{2}{*}{ Unit } & \multicolumn{4}{|c|}{ Mooring Identification } \\
\hline & & Mo3 & Mo2 & W3 & W4 \\
\hline Latitude $\phi$ & ${ }^{\circ} \mathbf{N}$ & 28.0 & 30.0 & 20.5 & 21.9 \\
\hline Longitude $\lambda$ & ${ }^{\circ} \mathbf{W}$ & -25.6 & -24.3 & -23.6 & -25.2 \\
\hline Depth & m & 166 & 140 & 200 & 220 \\
\hline Correlation coefficient $r_{\mathrm{A}}$ & & $0.90^{*}$ & $0.69^{*}$ & $0.32 \uparrow$ & 0.37 \\
\hline Standard deviation $e_{\mathrm{A}}$ & $\%$ & 24 & 55 & 161 & 119 \\
\hline Correlation coefficient $r_{\mathrm{D}}$ & & $0.89^{*}$ & $0.84^{*}$ & $0.40 \dagger$ & $0.71 *$ \\
\hline Standard deviation $e_{\mathrm{D}}$ & $\%$ & 28 & 41 & 114 & 50 \\
\hline Distance $L_{\mathrm{D}}$ & km & 8 & 68 & $\mathbf{0}$ & 62 \\
\hline Distance $L_{\mathrm{D}}$ & km & 72 & 68 & 12 & 72 \\
\hline Time shift $\tau_{\mathrm{A}}$ & days & $\mathbf{0}$ & 22 & $\mathbf{0}$ & -34 \\
\hline Time shift $\tau_{\mathrm{D}}$ & days & 30 & -22 & 5 & 40 \\
\hline Standard deviation $\sigma_{\mathrm{A}}$ & $\mathrm{cm} / \mathrm{s}$ & 3.5 & 4.2 & 4.0 & 3.5 \\
\hline Standard deviation $\sigma_{\mathrm{D}}$ & $\mathrm{cm} / \mathrm{s}$ & 3.4 & 2.6 & 3.0 & 5.7 \\
\hline Northward velocity $\vec{V}_{N}$ & $\mathrm{~cm} / \mathrm{s}$ & 2.7 & -2.2 & 0.3 & 0.8 \\
\hline Eastward velocity $u_{E}$ & $\mathrm{~cm} / \mathrm{s}$ & -0.5 & 0.2 & -0.1 & -0.6 \\
\hline
\end{tabular}

Parameters are as follows: $r_{\mathrm{A}}$ and $r_{\mathrm{D}}$ are correlation coefficients between ascending or descending track velocities and the corresponding projection of current meter velocities; $e_{\mathrm{A}}$ and $e_{\mathrm{D}}$ are standard deviation of the difference between altimetric "meter" and current meter, as a percentage of the standard deviation of the current meter velocities; $L_{\mathrm{A}}$ and $L_{\mathrm{D}}$ are distance between current meter and altimetric "meter"; $\tau_{\mathrm{A}}$ and $\tau_{\mathrm{D}}$ are time shift applied to current meter time series before computing correlation and percent error; $\sigma_{\mathrm{A}}$ and $\sigma_{\mathrm{D}}$ are standard deviation of the current meter data projected normal to the ascending or descending tracks; and $V_{\mathrm{N}}$ and $u_{E}$ are average current meter velocities over the itme of record.

*Different from zero with $99 \%$ confidence.

tDifferent from zero with $90 \%$ confidence.

in Figure 1. More detailed information on the mooring records and their data processing can be found in three expedition reports by Siedler et al. [1987], Müller et al. [1988], and Zenk et al. [1991].

Surface geostrophic velocities $v_{\mathrm{A}}$ normal to the altimeter's ground track were computed in the proximity of a current meter position from the altimeter sea level slopes over 100 to $150 \mathrm{~km}$ along the satellite's track, multiplied by the ratio of the gravity acceleration to the local Coriolis parameter. In symbols,

$$
\begin{array}{r}
v_{A}\left(t_{k}, \phi_{0}, \lambda_{0}\right)=(g / f)\left[h\left(t_{k}, \phi_{0}-d \phi, \lambda_{0}-d \lambda\right)\right. \\
\left.-h\left(t_{k}, \phi_{0}+d \phi, \lambda_{0}+d \lambda\right)\right] / D
\end{array}
$$

where $t_{k}=t_{0}+k \times 17.05$ days, $k=0,1, \cdots, 46$ are the times at which the satellite passed over the position with latitude $\phi_{0}$ and longitude $\lambda_{0}$ along the satellite's track, $g=$ $980 \mathrm{~cm} / \mathrm{s}^{2}, f=4 \pi \sin \left(\phi_{0}\right)$ day $^{-1}$, and $\left(\phi_{0}-d \phi, \lambda_{0}-d \lambda\right)$, $\left(\phi_{0}+d \phi, \lambda_{0}+d \lambda\right)$ are points along the satellite's track, separated by the distance $D$. In the remainder, we will refer to $\left(\phi_{0}, \lambda_{0}\right)$ as the position of the "altimetric meter." Because the time-averaged currents cannot be recovered from altimetry without very accurate knowledge of the geoid (except for strong meandering jets [see Kelly and Gille, 1990; Tai, 1990]) and because geoid estimates of such accuracy are unavailable, the time average of the current meter velocities was removed prior to subsequent computations.

Through experimentation it became clear that slopes computed over $D<90 \mathrm{~km}$ produced unstable time series of velocities. It also became clear that current meter velocities smoothed over times much shorter than 30 days had more energy than the altimetric velocities computed over $D>90$ $\mathrm{km}$. Overall, geostrophic velocities from slopes over 100-150 $\mathrm{km}$ and current meter data averaged over 30-60 days have the same energy level (variance) for this particular region, with minor differences when smoothing parameters are varied within these ranges. To obtain comparably smooth velocities from both the altimeter and the current meters, the $v_{\mathrm{A}}$ were interpolated to daily values with an exact cubic spline, and both the interpolated $v_{\mathrm{A}}$ and the daily averaged current meter velocities were smoothed with the same 30-day average (however, there are at most two independent pieces of information in each monthly altimetric average). The current velocities were rotated to obtain the component normal to the satellite's track, whose ascending tracks at $25^{\circ} \mathrm{N}$ latitude have an azimuth $a \cong 110^{\circ}$ (measured east to north),

$$
a=\sin ^{-1}\left[\left(\sin ^{2}(i)-\sin ^{2}(\phi)\right) /\left(1-\sin ^{2}(\phi)\right)\right]^{1 / 2}
$$

where $i$ is the satellite's inclination ( $107.94^{\circ}$ for Geosat) and $\phi$ is the latitude. The distance between the current meters and the nearest altimeter tracks used for comparison varied between 1 and $65 \mathrm{~km}$.

The moorings chosen for this comparison had longer time series available than other nearby moorings and carried a shallow instrument (see Table 1); the same criteria led us to include two moorings (Mo2, Mo3) that lie in a $250-\mathrm{km}$ band to the north of the region of interest but have the same energy level. Also, we specifically chose not to grid the data, or combine data from ascending and descending tracks, to yield clean comparisons.

Consider first the results for the ascending track under the Mo3 mooring (top row of Figure 4); this ascending track almost overflies the mooring (rightmost plot). The correlation between altimetric and in situ signals (leftmost plot) is 0.90 , which is significantly different from zero with $99 \%$ confidence and 13 degrees of freedom, assuming each 17-day sample is independent [e.g., Larsen and Marx, 1981]. The 

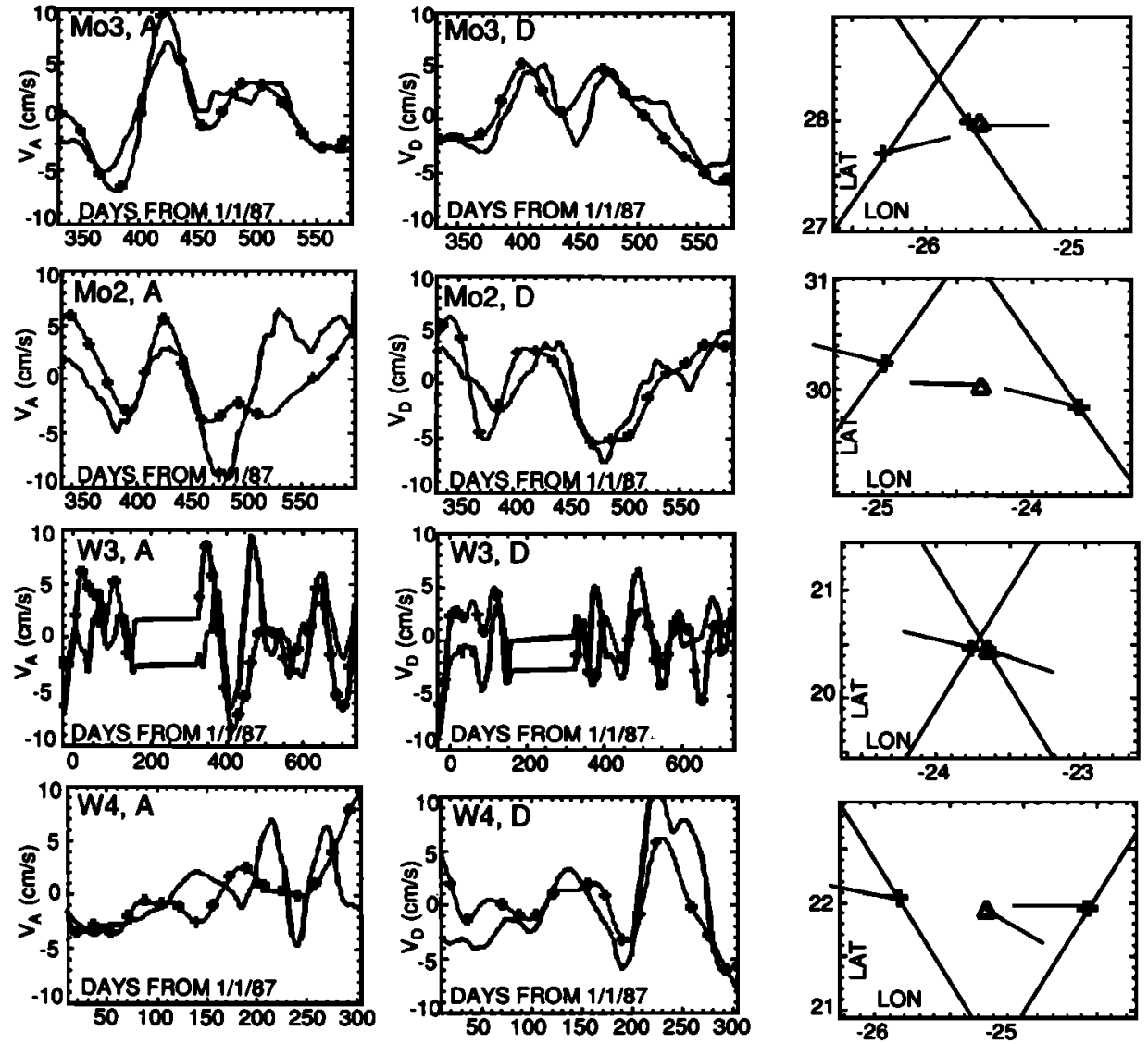

Fig. 4. Surface velocities (centimeters per second) normal to the altimeter tracks from altimetry (crosses) and from the shallowest current meters (thick line), versus time in days from November 1, 1987. A spline (thin line) connects the altimetric velocities as a visual aid. The left column is for the ascending track, the middle column is for the descending track, and the right column (latitude-longitude plot) shows the relative position of the mooring, the tracks, the chosen point along the tracks, and the direction of drift estimated from each of the three. Rows (top to bottom) are for mooring Mo3 position, no time shift; mooring Mo2 position, time shifted; mooring W3 position, no time shift; and mooring W4 position, time shifted. The plots of Mo2 and W4 have time shifts, described in Table 1, to account for the propagation of signals between the track positions and the mooring. See Table 1 for summary of properties.

variance of the 30-day-smoothed current meter time series is only $(3.0 \mathrm{~cm})^{2}$, and the variance of the difference between the two curves is $28 \%$ of the variance of the current meter.

Consider next the descending track for the same Mo3 mooring. Since it does not overfly the mooring, one is left with a choice of where along the track to position the "altimetric current meter." The simplest choice is that position with minimum distance to the mooring; however, through experimentation it became clear that other neighboring positions yield better correlation. The one we chose is shown in the rightmost panel in the top row of Figure 4. The middle panel shows the time series: it is clear that they are strongly correlated but they are also time shifted, with the current meter time series some $\mathbf{3 0}$ days ahead of the altimetric time series. Now it is clear why the closest distance to the current meter is not the best position: over the 250 days of this comparison, there must be an average propagation of sea level features, toward azimuth $90^{\circ}$ (measured from north to east), with a mean velocity of $1.6 \mathrm{~km} /$ day (the $48-\mathrm{km}$ distance between the altimetric meter and the mooring, divided by the 30-day time delay between the time series). By comparison, the current meter's time series has a mean velocity of $2.4 \mathrm{~km} /$ day towards azimuth $100^{\circ}$. With this time shift, the correlation between the two measurements is 0.89 , also significant with $99 \%$ confidence, and their discrepancy is $28 \%$ of the current meter variance.

Mooring Mo2, just $2^{\circ}$ to the north of Mo3, has a similar structure. When the time series of altimetric and current meter velocities, separated by over $60 \mathrm{~km}$, are offset in time to their position of best correlation (with the ascending velocities 22 days ahead of the current meter and the descending ones 22 days after), the implication is that there is a propagation of sea level features toward azimuth $290^{\circ}$ at a speed of $3 \mathrm{~km} /$ day; the current meter's mean velocity is 2.9 $\mathrm{km} /$ day toward $275^{\circ}$. The correlations, while lower $(0.69$ and 0.84), are still significant with $99 \%$ confidence, and the discrepancies are $55 \%$ and $41 \%$ of the current meter variance.

The results for the two southern moorings are completely different. W3 is precisely under an ascending track, just like Mo3, but its correlation is only 0.32 , significant with $90 \%$ confidence but leaving a discrepancy of $161 \%$ of the current meter variance. The result for the descending track near W3, which is under $10 \mathrm{~km}$ away, is similar: only 0.40 correlation (different from 0 with $95 \%$ confidence) but with a discrepancy of $114 \%$ of the current meter variance. The results for the W4 location, over $50 \mathrm{~km}$ away from any Geosat track, are also similar: correlations of 0.37 and 0.71 , the former 

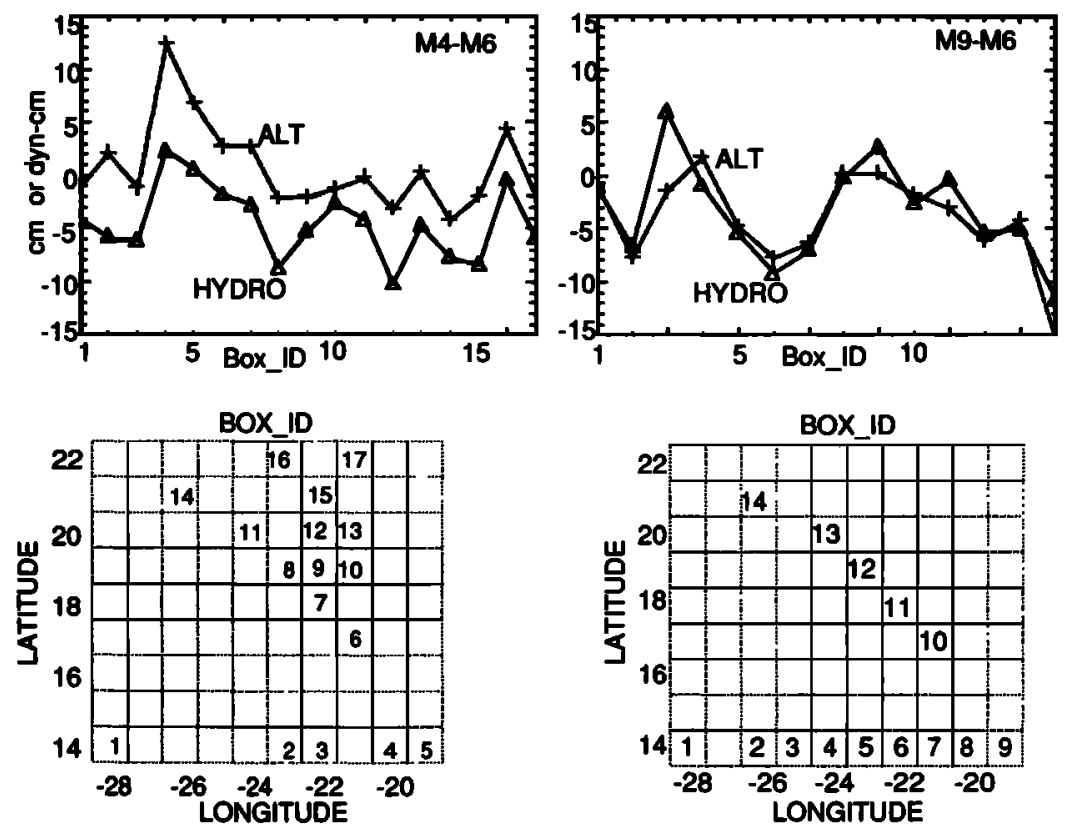

Fig. 5. (Top) Differences in dynamic height (dynamic centimeters) and in altimetric sea level (centimeters) within $1^{\circ}$ boxes, between (left) cruises M4 and M6 and (right) cruises M9 and M6. The horizontal axis is box number. (Bottom) Latitude-longitude distribution of the box numbers used in the comparison between (left) M4 and M6 and (right) M9 and M6.

indistinguishable from zero, the latter different with $99 \%$ confidence.

Table 1 summarizes the parameters found over all moorings. All time series are averaged over 30 days; altimeter heights are smoothed over $35 \mathrm{~km}$, and slopes are computed over $142 \mathrm{~km}$.

We could find no adequate explanation for the radically different agreement between the northern moorings and altimetry (excellent) versus the southern ones (for which a guess of zero velocity is a better estimate of the current meter's record than altimetry).

\section{AlTIMETRY AND HYDROGRAPHY}

Cruises 4, 6, and 9 of research vessel Meteor (M4, M6, and M9) visited this area during November 1986, November 1987, and February 1989, respectively, collecting hydrographic data on stations whose positions are shown in Figure 1. Dynamic topographies were obtained from dynamic heights $d$ of the 20-dbar surface relative to $1950 \mathrm{dbar}$.

The altimetry used in this section has one correction in addition to those described earlier: a second-degree alongtrack polynomial, between latitudes $0^{\circ}$ and $40^{\circ} \mathrm{N}$, was removed from the heights on each altimetric pass. This further minimizes residual orbit error, residual water vapor uncertainties, and residual tidal uncertainties. Our altimetryhydrography comparison without the removal of this polynomial was not encouraging.

To compare the dynamic topography and altimetric results, we concentrated not on the absolute dynamic height during one cruise (e.g., $d_{\mathrm{M} 6}$ ) but on the differences in dynamic height with respect to cruise M6, i.e.,

$$
\begin{aligned}
& d_{\mathrm{M} 4}-d_{\mathrm{M} 6}=d\left(\phi, \lambda, t_{\mathrm{M} 4}\right)-d\left(\phi, \lambda, t_{\mathrm{M} 6}\right) \\
& \mathrm{d}_{\mathrm{M} 9}-d_{\mathrm{M} 6}=d\left(\phi, \lambda, t_{\mathrm{M} 9}\right)-d\left(\phi, \lambda, t_{\mathrm{M} 6}\right)
\end{aligned}
$$

at latitude $\phi$, longitude $\lambda$, and time $t$. Those dynamic height differences were compared to the corresponding differences in sea level $h$ obtained from altimetry,

$$
\begin{aligned}
& h_{\mathrm{M} 4}-h_{\mathrm{M} 6}=h\left(\phi, \lambda, t_{\mathrm{M} 4}\right)-h\left(\phi, \lambda, t_{\mathrm{M} 6}\right) \\
& \mathrm{h}_{\mathrm{M} 9}-h_{\mathrm{M} 6}=h\left(\phi, \lambda, t_{\mathrm{M} 9}\right)-h\left(\phi, \lambda, t_{\mathrm{M} 6}\right)
\end{aligned}
$$

Such differences assume measurements at the same locations and different times. Unfortunately, the ship tracks did not repeat between cruises (see Figure 1). To present the simplest comparison, we averaged the dynamic heights for each cruise in boxes $1^{\circ}$ in latitude by $1^{\circ}$ in longitude, and we averaged the altimetry in boxes $1^{\circ}$ in latitude by $1^{\circ}$ in longitude by 1 month. We then differenced the $1^{\circ}$ grids only where both cruises had at least one station in the box. While each cruise had close to 60 stations, only 17 boxes were common to M4 and M6, and only 14 were common to M9 and M6, most of them with only one station per box.

As shown in Figure 5 , the differences $\left(\left(h_{\mathrm{M} 4}-h_{\mathrm{M} 6}\right)-\right.$ $\left.\left(d_{\mathrm{M} 4}-d_{\mathrm{M} 6}\right)\right)$ show an average offset of $5.2 \mathrm{~cm}$, while the average differences M9 - M6 agree within $0.7 \mathrm{~cm}$.

The average discrepancy between the times of M4 and M6 is most likely caused by a systematic difference between the TOVS estimate of water vapor, used up to June 1987 [Emery et al., 1990], and the SSM/I-based estimate used thereafter [Wentz, 1988]. The reasons for this conclusion are twofold: (1) when we performed this calculation with the much poorer Fleet Numerical Oceanography Center (FNOC) water vapor correction, which has no discontinuity between the M4 and M6 times, the discrepancies M4 - M6 and M9 - M6 had higher standard deviation $(3.1 \mathrm{~cm})$ but small bias for both M4 - M6 (0.1-cm bias) and M9 - M6 (2.0-cm bias); and (2) for this region, the water vapor path delay averaged over the whole region of Figure 2 for day 330 of 1986 is fully $4 \mathrm{~cm}$ (approximately $0.6 \mathrm{~g} / \mathrm{cm}^{2}$ of integrated water vapor) shorter 
than for the corresponding day of 1987 , while the average differences with the FNOC estimate is only $1.6 \mathrm{~cm}$.

In addition, at the suggestion of one reviewer, we computed the altimetric differences using only local nighttime data and only local daytime data, to assess whether the ionospheric correction (negligible at night) could be responsible: the areally averaged altimetric difference M4 - M6 was $0.4 \mathrm{~cm}$ using daytime data, and $0.6 \mathrm{~cm}$ using nighttime; the corresponding differences for M9 - M6 were 1.1 and $-0.6 \mathrm{~cm}$. Clearly, the ionospheric correction cannot be responsible for the 5.1-cm M4 - M6 difference. Furthermore, the $1.7-\mathrm{cm}$ M9 - M6 discrepancy between daytime or nighttime estimates is just as likely geographic variability, since for any particular month, the daytime and nighttime data tend to be concentrated in one subregion of the study area (Musman et al. [1990] also found negligible differences globally).

Remarkably, the standard deviation, measuring the agreement of each $1^{\circ}$ box after the overall mean is subtracted, is $2.1 \mathrm{~cm}$ for M4 - M6 and $2.6 \mathrm{~cm}$ for M9 - M6; i.e., the variance in the discrepancies corresponds to only $13 \%$ of the $(5.8 \mathrm{~cm})^{2}$ variance of the dynamic height differences. This agreement is rather remarkable, given the differences in physics (hydrography versus sea level), spatial and temporal sampling, and the errors in the measurements as discussed below.

Hydrography. The hydrography is referred to $1950 \mathrm{dbar}$. This value provides a good approximation for the mean flow in the region [Stramma, 1984a; Klein and Siedler, 1989], but it is not certain whether such a level is also appropriate for mesoscale current variability. In other words, there are barotropic components present in the sea level measured by altimetry that cannot be recovered from this hydrographic data set.

Temporal variability. In general, the altimetric satellite did not overfly any station visited by the ship while the station was being sampled. Because of the sampling properties of Geosat, the altimetric samples were obtained no farther than $82 \mathrm{~km}$ and 8.5 days from the station's place and time. We made three independent estimates of the effect of the temporal ocean variability: (1) from published eddy kinetic energy maps, (2) from the W4 current meter mooring, and (3) from one tide gage.

Eddy kinetic energy maps: From Richardson and Philander's [1987] eddy kinetic energy map, this region has between 200 and $400 \mathrm{~cm}^{2} / \mathrm{s}^{2}$. That translates to an rms velocity $v_{1} \sim(2 \times 300)^{1 / 2}=25 \mathrm{~cm} / \mathrm{s}$. Taking a length scale $L=40 \mathrm{~km}$, the first Rossby radius for the area from Emery et al. [1984], the rms height difference associated with $v_{1}$ is

$$
h_{1}=v_{1} L /(g / f)=5.6 \mathrm{~cm}
$$

Current meter: We filtered the time series from the W4 mooring's topmost current meter to pass periods between 10 and 60 days only to obtain a different estimate of rms velocity, $v_{2}$. This yielded $h_{2}=2.7 \mathrm{~cm}$.

Tide gage: A tide gage in the Canary Islands $\left(28^{\circ} 41^{\prime} \mathrm{N}\right.$, $17^{\circ} 45^{\prime} \mathrm{W}$ ) has rms differences between consecutive monthly averages of $h_{3}=4.3 \mathrm{~cm}$ (we could only obtain monthly averages from the Permanent Mean Sea Level Centre).

In summary, it is not possible to distinguish the $2.6-\mathrm{cm}$ standard deviation described above from what is expected by the natural variability of sea level, since the range of independent estimates is $2.7 \mathrm{~cm}$ to $5.6 \mathrm{~cm}$.
Tidal, orbit, and path errors in the altimetric data. Cartwright and Ray [1991], Jacobs et al. [1992] and Perigaud and Zlotnicki [1993] found M2 tidal errors of up to $10 \mathrm{~cm}$ in the Geosat data, correlated over five parallel neighboring ground tracks. However, all approaches to removing the error either remove part of the annual signal in sea level or leave a residual tidal error because of the close proximity between the alias period of M2 as sampled by Geosat (about 317 days) and the annual period. The second-degree polynomial removed from the data decreases this and the residual orbit errors but makes it difficult to quantify any residuals. The most significant path error in Geosat is due to water vapor, and Jourdan et al. [1990] show that even use of the SSM/Ibased correction leaves errors of $1-5 \mathrm{~cm}$ due to space-time variability of water vapor and the fact that Geosat and the DMSP satellite carrying the SSM/I did not sample the same locations at the same time.

\section{Summary and Discussion}

The comparison between surface geostrophic velocities estimated from sea level slopes over approximately $142 \mathrm{~km}$ with Geosat altimetry, and the velocities normal to the satellite tracks from four moored current meters no deeper than $220 \mathrm{~m}$ and averaged over $\mathbf{3 0}$ days, results in correlation coefficients ranging between 0.32 and 0.90 . Seven of the eight correlations were significantly different from zero at a 90\% confidence level, assuming normal probability distributions. The range masks a geographic discrepancy: the two northernmost moorings had correlations between 0.69 and 0.90 and errors between $24 \%$ and $55 \%$ of the current meter variance $\left(\sim(4 \mathrm{~cm})^{2}\right)$, while the two southernmost ones had the low correlations and discrepancies $>100 \%$. We could find no adequate explanation for this geographic difference.

Picaut et al. [1990] compared surface geostrophic currents derived from Geosat altimetry on and near the equator with current meter data from depths up to $50 \mathrm{~m}$. They used the meridional curvature of sea level on a beta plane, rather than its slope on an $f$ plane as is usual at higher latitudes, considered all altimetric data within a $4.5^{\circ}$ longitudinal band as colocated, and smoothed the time series with both a median filter and a 31-day Hanning window. They found correlations between the two data sets ranging from 0.5 to 0.8 , with a few as low as 0.2 ; the rms differences between the two methods ranged between 15 and $30 \mathrm{~cm} / \mathrm{s}$, relative to signals with 25 to $40 \mathrm{~cm} / \mathrm{s}$ rms. In the energetic Gulf Stream region, Joyce et al. [1990] compared absolute geostrophic velocities derived from Geosat in a 2-week period and those derived from acoustic Doppler current profiler (ADCP), smoothed with a filter whose half power point was at $76 \mathrm{~km}$, and without time smoothing. They found correlations of 0.87 and 0.57 between the two data types on two particular days; they do not quote the rms difference between the two measurements. In a quieter regime, Stammer et al. [1991] also found agreement between altimetric and current meter velocities (their Figures 8 and 9), although they did not quantify it.

When all these studies are viewed together, it is clear that the altimetrically derived geostrophic velocities seldom have correlations below 0.5 or higher than 0.9 when compared with shallow current meters or Doppler profilers. It is also clear that for the low-current zone investigated here and with the methods used here, Geosat altimetry can measure sur- 
face geostrophic velocities averaged over 30 days and 142 $\mathrm{km}$ with rms error not exceeding $2-3 \mathrm{~cm} / \mathrm{s}$. More work needs to be done to understand the geographic sensitivity.

We also compared time differences in altimetric sea level residuals, e.g., $h_{\mathrm{M} 4}-h_{\mathrm{M} 6}$, with time differences in dynamic heights ( $20 \mathrm{dbar}$ to $1950 \mathrm{dbar}$ ), e.g., $d_{\mathrm{M} 4}-d_{\mathrm{M} 6}$. Both $d$ and $h$ were averaged over $1^{\circ}$ boxes, and $h$ was also averaged over 1 month.

Let us assume for a moment that dynamic height differences in dynamic centimeters measure sea level differences in centimeter. The areal average of $\left(\left(h_{\mathrm{M} 4}-h_{\mathrm{M} 6}\right)-\left(d_{\mathrm{M} 4}-\right.\right.$ $\left.d_{\mathrm{M} 6}\right)$ ) is a systematic bias of $5.1 \mathrm{~cm}$, while the corresponding average for $\left(\left(h_{\mathrm{M} 9}-h_{\mathrm{M} 6}\right)-\left(d_{\mathrm{M} 9}-d_{\mathrm{M} 6}\right)\right)$ is $0.7 \mathrm{~cm}$. The standard deviation of the altimetric-dynamic height differences was $2.1 \mathrm{~cm}$, only $13 \%$ of the variance in the dynamic height differences.

We find a systematic difference between the TOVS and SSM/I water vapor corrections responsible for the bias between M4 and M6 times for two reasons: (1) the poorer FNOC water vapor correction, which has no discontinuity between the M4 and M6 times, yields discrepancies M4 M6 and M9 - M6 with $3.1 \mathrm{~cm}$ standard deviation but only $0.1 \mathrm{~cm}$ bias between M4 and M6; and (2) averaged over this region, the water vapor path delay for day 330 of 1986 is $4 \mathrm{~cm}$ shorter than for the corresponding day of 1987, while the average difference with FNOC is only $1.6 \mathrm{~cm}$.

We also find that the 2.1-cm standard deviation of the differences $\left(\left(h_{\mathrm{M} x}-h_{\mathrm{M} 6}\right)-\left(d_{\mathrm{Mx}}-d_{\mathrm{M} 6}\right)\right)$ is indistinguishable from the $2.7-\mathrm{cm}$ to $5.6-\mathrm{cm}$ natural variability of sea level in the area expected between the times when the ship sampled the ocean and when the satellite did.

Of course, dynamic heights with respect to a level of no motion are physically different from sea level. One source of uncertainty is the level of no motion; unfortunately, the ship tracks did not lend themselves to either a stable beta spiral calculation [Stommel and Schott, 1977] or an inverse calculation [Wunsch, 1978]. Having both hydrography and current data, one can, in principle, obtain the velocity at the reference level from the current meters, but the mooring time series used here did not cover the 28 months needed to overlap all three hydrographic cruises in order to measure interannual differences in dynamic height.

The water vapor correction affected the hydrographic comparison because Geosat did not carry a nadir-looking microwave radiometer to measure the concentration of water vapor along the altimetric path (as did the previous Seasat satellite [Tapley et al., 1982] as well as currently flying satellites). The TOVS- and SSM/I-based corrections are demonstrably better than the one based on the surface humidity of the FNOC model because the equation used to convert FNOC surface humidity to water vapor integrated over about $20 \mathrm{~km}$ of troposphere fails to account for deep atmospheric convection [Liu et al., 1991, 1992]. However, systematic differences between the TOVS estimate and the more accurate SSM/I estimate appear responsible for our biased M4 - M6 differences.

The systematic deviations for the surface topography between the three years of the Meteor cruises with same sign and similar magnitude in both the altimetry and the dynamic topography indicate that altimetric data can be used to determine interannual changes of the mean circulation, even in a low-velocity regime.
Acknowledgments. A. Hayashi was instrumental in the processing of the Geosat data. The IDL software (Research Systems, Inc., 1991) greatly helped the analysis. Assistance in the data processing of the in situ data was received from the Marine Physics group of the Institut für Meereskunde in Kiel. Collaboration in this study was facilitated by the second author's (G.S.) stay as a visiting scientist at the Jet Propulsion Laboratory. This work was performed in part at the Jet Propulsion Laboratory, California Institute of Technology, under contract with the National Aeronautics and Space Administration. This work was supported by NASA's Climate and Hydrologic Systems Program, by the Topex/Poseidon Project (V.Z.) and by the Deutsche Forschungsgemeinschaft, SFB 133 (G.S., B.K.).

\section{REFERENCES}

Arnault, S., Y. Ménard, and J. Merle, Observing the tropical Atlantic Ocean in 1986-1987 from altimetry, J. Geophys. Res., 95(C10), 17,921-17,945, 1990.

Barton, E. D., Meanders, eddies and intrusions in the thermohaline front off northwest Africa, Oceanol. Acta, 10, 267-282, 1987.

Cartwright, D. E., and R. D. Ray, Oceanic tides from Geosat altimetry, J. Geophys. Res., 95(C3), 3069-3090, 1991.

Cheney, R. E., B. C. Douglas, R. W. Agreen, L. L. Miller, and D. L. Porter, Geosat altimeter geophysical data record (GDR) user handbook, NOAA Tech. Memo. NOS-NGS-46, Natl. Ocean Serv., Rockville, Md., 1987.

Cheney, R. E., W. J. Emery, B. J. Haines, and F. Wentz, Recent improvements in Geosat altimeter data, Eos Trans. AGU, 72, 577, 1991.

Davis, R. E., On estimating velocity from hydrogaphic data, $J$. Geophys. Res., 83(C11), 5507-5509, 1978.

Emery, W. J., W. G. Lee, and L. Magaard, Geographic and seasonal distribution of Brunt-Väisälä frequency and Rossby radii in the North Pacific and North Atlantic, J. Phys. Oceanogr., 14(2), 294-317, 1984.

Emery, W. J., G. H. Born, D. G. Baldwin, and C. Norris, Satellitederived water vapor corrections for Geosat altimetry, J. Geophys. Res., 95(C3), 2953-2964, 1990.

Fiekas, V., J. Elken, T. J. Müller, A. Aitsam, and W. Zenk, A view of the Canary Basin thermocline circulation in winter, J. Geophys. Res., 97(C8), 12,495-12,510, 1992.

Haines, B. J., G. H. Born, G. W. Rosborough, and J. G. Marsh, Precise Geosat orbits for the Geosat Exact Repeat Mission, $J$. Geophys. Res., 95(C3), 2857-2870, 1990.

Jacobs, G., G. Born, M. Parke, and P. C. Allen, The global structure of the annual and semiannual sea surface height variability from Geosat altimeter data, J. Geophys. Res., 97(C11), 17,813-17,828, 1992.

Jourdan, D., C. Boissier, A. Braun, and J.-F. Minster, Influence of the wet tropospheric correction in mesoscale dynamic topography as derived from satellite altimetry, J. Geophys. Res., 95(C10), $17,993-18,004,1990$.

Joyce, T. M., K. A. Kelly, D. M. Schubert, and M. J. Caruso, Shipboard and altimetric studies of rapid Gulf Stream variability between Cape Cod and Bermuda, Deep Sea Res., 37(6), 897-910, 1990.

Kelly, K. A., and S. T. Gille, Gulf Stream surface transport and statistics at $69^{\circ} \mathrm{W}$ from the Geosat altimeter, J. Geophys. Res., 95(C3), 3149-3161, 1990.

Klein, B., and G. Siedler, On the origin of the Azores Current, $J$. Geophys. Res., 94(C5), 6159-6168, 1989.

Larsen, R. J., and M. L. Marx, An Introduction to Mathematical Statistics and Its Applications, 596 pp., Prentice Hall, Englewood Cliffs, N. J., 1981.

Liu, W. T., W. Tang, and P. P. Niiler, Humidity profiles over the ocean, J. Clim., 4(11), 1023-1034, 1991.

Liu, W. T., W. Tang, and F. Wentz, Precipitable water and surface humidity over global oceans from special sensor microwave imager and European Center for Medium Range Weather Forecasts, J. Geophys. Res., 97(C2), 2251-2264, 1992.

Luyten, J. R., J. Pedlosky, and H. Stommel, The ventilated thermocline, J. Phys. Oceanogr., 13, 292-309, 1983.

Marsh, J. G., et al., The GEM-T2 gravitational model, J. Geophys. Res., 95(B13), 22,043-22,071, 1990.

May, D. A., and J. D. Hawkins, Impact of the Geosat altimeter wet tropospheric range correction in the Greenland-IcelandNorwegian Sea, J. Geophys. Res., 96(C4), 7237-7247, 1991. 
Müller, T. J., and G. Siedler, Multi-year current time series in the eastern North Atlantic Ocean, J. Mar. Res., 50, 1-37, 1992.

Müller, T. J., G. Siedler, and W. Zenk, Forschungsschiff Meteor, Reise Nr. 6, Atlantik 87/88, Fahrtabschnitte Nr. 1-3, OktoberDezember 1987, Berichte der wissenschaftlichen Leiter, Ber. Inst. Meereskd., 184, 77 pp., Univ. Kiel, Kiel, Germany, 1988.

Musman, S., A. Drew, and B. Douglas, Ionospheric effects on Geosat altimeter observations, J. Geophys. Res., 95(C3), 29652968, 1990.

Onken, R., and B. Klein, A model of baroclinic instability and waves between the ventilated gyre and the shadow zone of the North Atlantic Ocean, J. Phys. Oceanogr., 21(1), 53-67, 1991.

Perigaud, C., and V. Zlotnicki, Importance of Geosat orbit and tidal errors for large scale Indian Ocean observations, Oceanol. Acta, in press, 1993.

Picaut, J., A. J. Busalacchi, M. J. McPhaden, and B. Camusat, Validation of the geostrophic method for estimating zonal currents at the equator from Geosat altimeter data, J. Geophys. Res., 95(C3), 3015-3024, 1990.

Rapp, R. H., The determination of geoid undulations and gravity anomalies from Seasat altimeter data, J. Geophys. Res., 88(C3), 1552-1562, 1983.

Research Systems, Inc., IDL User's Guide, 480 pp., Boulder, Colo., 1991.

Richardson, P. L., and S. G. H. Philander, The seasonal variations of surface currents in the tropical Atlantic Ocean: A comparison of ship drift data with results from a general circulation model, $J$. Geophys. Res., 92(C1), 715-724, 1987.

Sandwell, D. T., D. G. Milbert, and B. C. Douglas, Global nondynamic orbit improvement for altimetric satellites, J. Geophys. Res., 91(C8), 9447-9451, 1986.

Siedler, G., and U. Paul, Barotropic and baroclinic tidal currents in the eastern basins of the North Atlantic, J. Geophys. Res., 96(C12), 22,259-22,271, 1991.

Siedler, G., H. Schmickler, T. J. Müller, H.-W. Schenke, and W. Zenk, Forschungsschiff Meteor, Reise Nr. 4, Kapverden Expedition Oktober-Dezember 1986, Ber. Inst. Meereskd., 173, 123 pp., Univ. Kiel, Kiel, Germany, 1987.

Siedler, G., N. Zangenberg, R. Onken, and A. Morlière: Seasonal changes in the tropical Atlantic circulation: Observation and simulation of the Guinea Dome, J. Geophys. Res., 97(C1), 703715, 1992.

Stammer, D., H.-H. Hinrichsen, and R. H. Käse, Can meddies be detected by satellite altimetry?, J. Geophys. Res., 96(C4), 70057014, 1991.

Stommel, H., and F. Schott, The Beta spiral and the determination of the absolute velocity field from hydrographic station data, Deep Sea Res., 24(3), 325-329, 1977.

Stramma, L., Geostrophic transport in the warm water sphere of the eastem subtropical North Atlantic, J. Mar. Res., 42, 537-558, $1984 a$.

Stramma, L., Potential vorticity and volume transport in the eastern
North Atlantic from two long CTD sections, Dtsch. Hydrogr. $Z$., 37(4), 147-155, $1984 b$.

Stramma, L., and T. J. Müller, Some observations of the Azores Current and the North Equatorial Current, J. Geophys. Res., 94(C3), 3181-3186, 1989.

Tai, C.-K., Estimating the surface transport of meandering jet streams from satellite altimetry: Surface transport estimates for the Gulf Stream and Kuroshio extension, J. Phys. Oceanogr., 20(6), 860-879, 1990.

Tai, C.-K., How to observe the gyre to global scale variability in satellite altimetry: Signal attenuation by orbit error removal, $J$. Atmos. Oceanic Technol., 8, 271-288, 1991.

Tapley, B., Fundamentals of orbit determination, in Theory of Satellite Geodesy and Gravity Field Determination, Lect. Notes in Earth Sci., vol. 25, edited by F. Sansò and R. Rummel, pp. 235-260, Springer-Verlag, New York, 1989.

Tapley, B. D., J. B. Lundberg, and G. H. Born, The Seasat altimeter wet tropospheric range correction, J. Geophys. Res., 87(C5), 3213-3220, 1982.

Wentz, F. J., Water vapor length correction for altimeters, in U.S. WOCE Tech. Rep. 2, edited by D. Chelton, appendix, pp. 1-9, U.S. Plann. Off. for WOCE, College Station, Tex., 1988.

Wentz, F. J., User's manual SSM/I geophysical tapes, RSS Tech. Rep. 060989, 16 pp., Remote Sens. Syst., Santa Rosa, Calif., 1989.

Wunsch, C., The North Atlantic general circulation west of $50^{\circ} \mathrm{W}$ determined by inverse methods, Rev. Geophys., 16, 583-620, 1978.

Wunsch, C., Global-scale sea surface variability from combined altimetric and tide gage measurements, J. Geophys. Res., 96(C8), $15,023-15,082,1991$.

Zenk, W., B. Klein, and M. Schröder, Cape Verde Frontal Zone, Deep Sea Res., 38, suppl. 1, S505-S530, 1991.

Zlotnicki, V., Sea level differences across the Gulf Stream and Kuroshio extension, J. Phys. Oceanogr., 21(4), 599-609, 1991.

Zlotnicki, V., L.-L. Fu, and W. Patzert, Seasonal variability in global sea level observed with Geosat altimetry, J. Geophys. Res., 94(C12), 17,959-17,970, 1989.

Zlotnicki, V., A. Hayashi, and L.-L. Fu, The JPL-Oceans 8902 version of Geosat altimetry data, JPL Internal Doc. D-6939, Jet Propul. Lab., Calif. Inst. of Technol., Pasadena, 1990.

B. Klein and G. Siedler, Institut für Meereskunde an der Universität Kiel, Düsternbrooker Weg 20, D-2300 Kiel 1, Germany.

V. Zlotnicki, Jet Propulsion Laboratory, M/S 300-323, California Institute of Technology, Pasadena, CA 91109.

(Received September 22, 1992;

revised November 17, 1992;

accepted November 17, 1992.) 